\title{
ANALIZA KINEMATYKI MANIPULATORA O PIECCIU STOPNIACH SWOBODY
}

\begin{abstract}
W artykule przestawiono analizę kinematyki manipulatora o pięciu stopniach swobody na przykładzie jednostki kinematycznej robota manipulacyjnego Scorbot-ER 4 pc. Do opisu kinematyki układu zastosowano notację Denavita-Hartenberga. Przyjęto schemat kinematyki manipulatora i podano parametry opisujące układ. Zapisano odpowiednie macierze transformacji, które zastosowano w dalszej analizie. Wyznaczono jakobian analityczny manipulatora oraz jakobian geometryczny w ciele i przeprowadzono analizę osobliwości. Są to takie konfiguracje manipulatora, w których wyznaczenie rozwiązania zadania odwrotnego kinematyki jest znacznie utrudnione, a przy zastosowaniu klasycznych metod - niemożliwe. Dlatego znajomość konfiguracji osobliwych jest niezbędna w celu poprawnego planowania i generowania trajektorii manipulatora. Zaprezentowana metodyka jest uniwersalna i może być stosowana do analizy kinematyki manipulatorów o innej strukturze kinematycznej niż zaprezentowana w niniejszej pracy.
\end{abstract}

Słowa kluczowe: jakobian, konfiguracje osobliwe, notacja Denavita-Hartenberga

\section{Wprowadzenie}

Analizę kinematyki manipulatora przeprowadza się w celu uzyskania opisu właściwości ruchowych układu, które mogą być wykorzystane w planowaniu trajektorii ruchu oraz jej realizacji, czyli sterowaniu [1, 2]. Analiza kinematyki umożliwia również określenie charakterystycznych dla danego manipulatora tzw. jakobianów, które stosuje się np. do obliczenia wpływu sił i momentów zewnętrznych działających na końcówkę manipulatora na siły i momenty w przegubach. Jakobiany mogą być też użyte do uzyskania informacji o tzw. konfiguracjach osobliwych, czyli ustawieniach łańcucha kinematycznego, których należy unikać na etapie planowania trajektorii, ze względu na niejednoznaczne rozwiązania zadania odwrotnego kinematyki.

W artykule dokonano analizy kinematyki manipulatora robota Scorbot-ER 4pc. Jednostka kinematyczna robota to czteroczłonowy manipulator o pięciu

\footnotetext{
${ }^{1}$ Autor do korespondencji/corresponding author: Piotr Gierlak, Politechnika Rzeszowska, al. Powstańców Warszawy 8, 35-959 Rzeszów, tel.: (17) 8651854, e-mail: pgierlak@prz.edu.pl
} 
stopniach swobody $-\mathrm{z}$ możliwością jednoczesnego wykonywania obrotów ostatniego członu wokół dwóch prostopadłych osi. Ramię manipulatora o trzech stopniach swobody ma strukturę kinematyczną antropomorficzną (stawowa) [3]. $\mathrm{Na}$ końcu ramienia jest dołączona tzw. kiść o dwóch stopniach swobody. Formalnie wygodnie jest przyjąć, że manipulator jest pięcioczłonowy, natomiast czwarty człon manipulatora ma zerową długość i masę.

\section{Przekształcenia jednorodne}

Do opisu kinematyki manipulatora zastosowano notację Denavita-Hartenberga (D-H) [4-6]. Na schemacie kinematycznym (rys. 1.) przyjętym zgodnie z notacją, wprowadzono lokalne układy odniesienia związane z kolejnymi członami i określono parametry kinematyczne charakteryzujące układ. W notacji D-H wprowadza się tzw. macierz przekształcenia jednorodnego [4-6] $\mathbf{A}_{i-1}^{i}$, która przekształca współrzędne wybranego punktu z układu $i$-tego do $(i-1)$. Jest ona wynikiem czterech przekształceń ,podstawowych” [6], co zapisano jako:

$$
\begin{aligned}
\mathbf{A}_{i-1}^{i} & =\mathbf{R o t}_{z, \theta i} \text { Trans }_{z, d i} \text { Trans }_{x, a i} \mathbf{R o t}_{x, \alpha i}= \\
& =\left[\begin{array}{cccc}
c_{\theta i} & -s_{\theta i} & 0 & 0 \\
s_{\theta i} & c_{\theta i} & 0 & 0 \\
0 & 0 & 1 & 0 \\
0 & 0 & 0 & 1
\end{array}\right]\left[\begin{array}{cccc}
1 & 0 & 0 & 0 \\
0 & 1 & 0 & 0 \\
0 & 0 & 1 & d_{i} \\
0 & 0 & 0 & 1
\end{array}\right]\left[\begin{array}{cccc}
1 & 0 & 0 & a_{i} \\
0 & 1 & 0 & 0 \\
0 & 0 & 1 & 0 \\
0 & 0 & 0 & 1
\end{array}\right]\left[\begin{array}{cccc}
0 & 0 & 0 & 0 \\
0 & c_{\alpha i} & -s_{\alpha i} & 0 \\
0 & s_{\alpha i} & c_{\alpha i} & 0 \\
0 & 0 & 0 & 1
\end{array}\right]= \\
& =\left[\begin{array}{cccc}
c_{\theta i} & -s_{\theta i} c_{\alpha i} & s_{\theta i} s_{\alpha i} & a_{i} c_{\theta i} \\
s_{\theta i} & c_{\theta i} c_{\alpha i} & -c_{\theta i} s_{\alpha i} & a_{i} s_{\theta i} \\
0 & s_{\alpha i} & c_{\alpha i} & d_{i} \\
0 & 0 & 0 & 1
\end{array}\right]
\end{aligned}
$$

gdzie: $s_{\theta i}=\sin \theta_{i}, c_{\theta i}=\cos \theta_{i}, s_{\alpha i}=\sin \alpha_{i}, c_{\alpha i}=\cos \alpha_{i}, \operatorname{Rot}_{z, \theta i}-$ macierz rotacji o kąt $\theta_{i}$ wokół osi $z$, Trans rddi $_{z}-$ macierz translacji o $d_{i}$ wzdłuż osi $z$, Trans $_{x, a i}-$ macierz translacji o $a_{i}$ wzdłuż osi $x$, Rot $_{x, a i}$ - macierz rotacji o kąt $\alpha_{i}$ wokół osi $x$.

Rotacje i translacje są rozumiane jako rotacje i translacje układu $i$-tego względem $(i-1)$. Ogniwo $i$-te łańcucha kinematycznego jest charakteryzowane przez cztery parametry: $a_{i}$ - długość członu, $\alpha_{i}$ - skręcenie członu, $d_{i}$ - odsunięcie przegubu, $\theta_{i}$ - kąt obrotu przegubu. Parametry manipulatora w ujęciu notacji D-H zestawiono w tab. 1. 


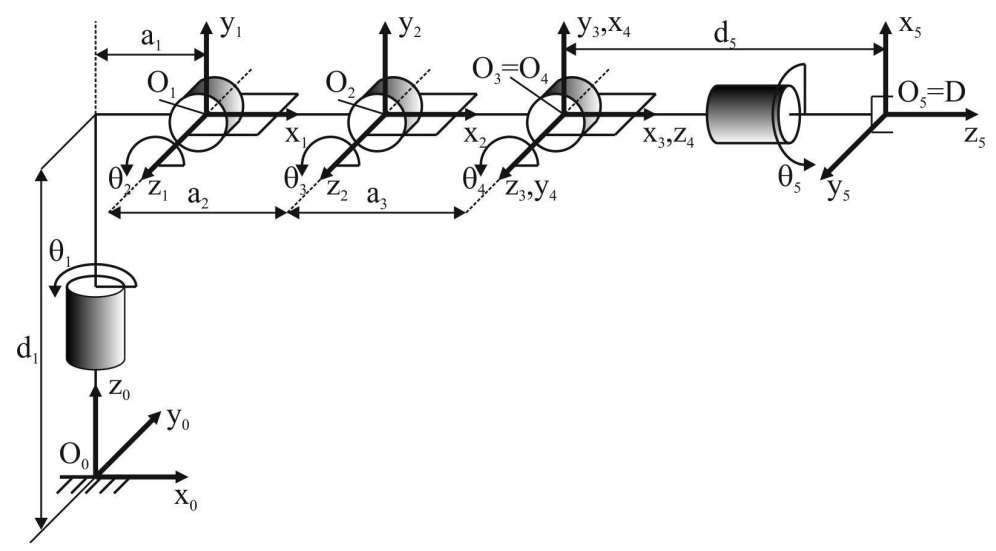

Rys. 1. Struktura kinematyczna manipulatora Scorbot-ER 4pc

Fig. 1. Kinematic structure of the Scorbot-ER 4pc manipulator

Tabela 1. Parametry kinematyczne manipulatora Scorbot-ER 4pc

Table 1. Kinematics parameters of the Scorbot-ER 4pc manipulator

\begin{tabular}{|c|c|c|c|c|}
\hline Nr ogniwa & $\boldsymbol{a}_{\boldsymbol{i}}$ & $\boldsymbol{\alpha}_{\boldsymbol{i}}$ & $\boldsymbol{d}_{\boldsymbol{i}}$ & $\boldsymbol{\theta}_{\boldsymbol{i}}$ \\
\hline 1 & $l_{1}$ & $\pi / 2$ & $d_{1}$ & $\theta_{1}$ \\
\hline 2 & $l_{2}$ & 0 & 0 & $\theta_{2}$ \\
\hline 3 & $l_{3}$ & 0 & 0 & $\theta_{3}$ \\
\hline 4 & 0 & $\pi / 2$ & 0 & $\pi / 2+\theta_{4}$ \\
\hline 5 & 0 & 0 & $d_{5}$ & $\theta_{5}$ \\
\hline
\end{tabular}

Macierze przekształceń jednorodnych mają następujące postacie:

$$
\begin{aligned}
\mathbf{A}_{0}^{1} & =\left[\begin{array}{cccc}
\cos \theta_{1} & 0 & \sin \theta_{1} & l_{1} \cos \theta_{1} \\
\sin \theta_{1} & 0 & -\cos \theta_{1} & l_{1} \sin \theta_{1} \\
0 & 1 & 0 & d_{1} \\
0 & 0 & 0 & 1
\end{array}\right] \\
\mathbf{A}_{1}^{2} & =\left[\begin{array}{cccc}
\cos \theta_{2} & -\sin \theta_{2} & 0 & l_{2} \cos \theta_{2} \\
\sin \theta_{2} & \cos \theta_{2} & 0 & l_{2} \sin \theta_{2} \\
0 & 0 & 1 & 0 \\
0 & 0 & 0 & 1
\end{array}\right]
\end{aligned}
$$




$$
\begin{aligned}
\mathbf{A}_{2}^{3} & =\left[\begin{array}{cccc}
\cos \theta_{3} & -\sin \theta_{3} & 0 & l_{3} \cos \theta_{3} \\
\sin \theta_{3} & \cos \theta_{3} & 0 & l_{3} \sin \theta_{3} \\
0 & 0 & 1 & 0 \\
0 & 0 & 0 & 1
\end{array}\right] \\
\mathbf{A}_{3}^{4} & =\left[\begin{array}{cccc}
-\sin \theta_{4} & 0 & \cos \theta_{4} & 0 \\
\cos \theta_{4} & 0 & \sin \theta_{4} & 0 \\
0 & 1 & 0 & 0 \\
0 & 0 & 0 & 1
\end{array}\right] \\
\mathbf{A}_{4}^{5} & =\left[\begin{array}{cccc}
\cos \theta_{5} & -\sin \theta_{5} & 0 & 0 \\
\sin \theta_{5} & \cos \theta_{5} & 0 & 0 \\
0 & 0 & 1 & d_{5} \\
0 & 0 & 0 & 1
\end{array}\right]
\end{aligned}
$$

Do wyznaczenia jakobianu analitycznego i geometrycznego potrzebna jest znajomość macierzy transformacji układu $j$-tego do $(i-1)$ [7]:

$$
\mathbf{T}_{i-1}^{j}=\prod_{k=i}^{j} \mathbf{A}_{k-1}^{k}
$$

a ogólna struktura macierzy $\mathbf{T}_{i-1}^{j}$ to:

$$
\mathbf{T}_{i-1}^{j}=\left[\begin{array}{c|c}
\mathbf{R}_{i-1}^{j} & \mathbf{p}_{i-1}^{j} \\
\hline \mathbf{0} & 1
\end{array}\right]
$$

gdzie: $\mathbf{R}_{i-1}^{j} \in \mathfrak{R}^{3 \times 3}$ - macierz rotacji układu $j$-tego względem $(i-1), \mathbf{p}_{i-1}^{j} \in \mathfrak{R}^{3}$ - wektor translacji układu $j$-tego względem $(i-1)$.

\section{Jakobian analityczny}

W wielu aspektach robotyki, takich jak modelowanie, planowanie ruchu i sterowanie manipulatorem [2] stosuje się tzw. macierz jakobianową, nazywaną jakobianem (w robotyce nie utożsamia się jej z wyznacznikiem macierzy jakobianowej, jak to ma miejsce w matematyce). W literaturze zdefiniowano kilka 
rodzajów jakobianów [6-8]. W tym rozdziale zostanie przedstawiony jakobian analityczny, natomiast w kolejnym - jakobian geometryczny w ciele.

Do wyznaczenia jakobianu analitycznego wykorzystuje się tzw. funkcję kinematyki, która wynika ze związku pomiędzy współrzędnymi konfiguracyjnymi (przegubowymi) a współrzędnymi zadaniowymi związanymi z przestrzenią roboczą (zadaniowa). Współrzędne zadaniowe y mogą być wybrane np. tak, aby określały pozycję i orientację końcówki roboczej w przestrzeni zadaniowej w funkcji współrzędnych konfiguracyjnych:

$$
\mathbf{y}=\mathbf{k}(\mathbf{q}) \in \mathfrak{R}^{m}
$$

gdzie: $\mathbf{k}(\mathbf{q})$ - tzw. funkcja kinematyki, $\mathbf{q} \in \mathfrak{R}^{n}$ - wektor współrzędnych konfiguracyjnych, $n$ - wymiar przestrzeni konfiguracyjnej manipulatora, $m$ - wymiar przestrzeni zadaniowej manipulatora.

Wybór współrzędnych zadaniowych y do reprezentacji kinematyki ma istotny wpływ na złożoność reprezentacji kinematyki [7].

Zależność pomiędzy prędkościami przegubowymi i prędkościami w przestrzeni zadaniowej jest określona za pomoca jakobianu analitycznego, co zapisano następująco:

$$
\dot{\mathbf{y}}=\mathbf{J}^{a}(\mathbf{q}) \dot{\mathbf{q}}, \quad \mathbf{J}^{a}(\mathbf{q})=\frac{\partial \mathbf{k}(\mathbf{q})}{\partial \mathbf{q}} \in \mathfrak{R}^{m \times n}
$$

gdzie: $\dot{\mathbf{q}} \in \mathfrak{R}^{n}$ - wektor prędkości przegubowych, $\dot{\mathbf{y}} \in \mathfrak{R}^{m}$ - prędkość we współrzędnych zadaniowych, $\mathbf{J}^{a}(\mathbf{q})$ - macierz jakobianowa reprezentacji kinematyki manipulatora we współrzędnych, nazywana jakobianem analitycznym manipulatora.

Do wyznaczenia jakobianu analitycznego zastosowano jeden z możliwych sposobów, przedstawiony m.in. w pracach [6, 7]. Jakobian analityczny $n$-członowego manipulatora składa się z kolumn $\mathbf{J}_{i}^{a}, i=1,2, \ldots, n$, czyli:

$$
\mathbf{J}^{a}(\mathbf{q})=\left[\begin{array}{lllll}
\mathbf{J}_{1}^{a} & \ldots & \mathbf{J}_{i}^{a} & \ldots & \mathbf{J}_{n}^{a}
\end{array}\right]
$$

gdzie kolumnę $\mathbf{J}_{i}^{a}$ określa się jako:

$$
\mathbf{J}_{i}^{a}=\left[\begin{array}{c}
\mathbf{R}_{03 k o l}^{i-1} \times\left(\mathbf{p}_{0}^{n}-\mathbf{p}_{0}^{i-1}\right) \\
\mathbf{R}_{03 k o l}^{i-1}
\end{array}\right]
$$

w przypadku gdy przegub $i$-ty jest obrotowy lub 


$$
\mathbf{J}_{i}^{a}=\left[\begin{array}{c}
\mathbf{R}_{03 k o l}^{i-1} \\
\mathbf{0}
\end{array}\right]
$$

w przypadku gdy przegub $i$-ty jest pryzmatyczny.

Elementy wzorów (12) i (13) wyznacza się na podstawie macierzy transformacji (8). Symbolem $\mathbf{R}_{0}^{i-1} 3 \mathrm{kol}$ oznaczono trzecią kolumnę macierzy rotacji.

W przypadku rozważanego manipulatora przyjęto 6-wymiarową przestrzeń

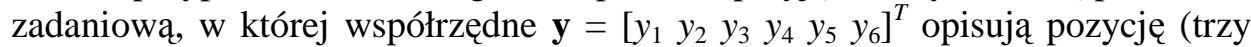
pierwsze elementy) i orientację (trzy ostatnie elementy) końcówki roboczej względem osi układu bazowego. Ze względu na specyficzny sposób pomiaru kątów obrotu członów manipulatora robota Scorbot-ER 4pc przyjęto nowy wektor współrzędnych konfiguracyjnych:

$$
\mathbf{q}=\left[\begin{array}{c}
q_{1} \\
q_{2} \\
q_{3} \\
q_{4} \\
q_{5}
\end{array}\right]=\left[\begin{array}{c}
\theta_{1} \\
\theta_{2} \\
\theta_{2}+\theta_{3} \\
\theta_{2}+\theta_{3}+\theta_{4} \\
\theta_{5}
\end{array}\right]
$$

Specyfika pomiaru kątów obrotu członu 3. i 4. polega na tym, że kąty obrotu tych członów nie są odmierzane względem osi $x_{i}$ członów poprzedzających, lecz względem poziomej płaszczyzny $x_{0} y_{0}$ układu bazowego. Jakobian analityczny wyprowadzony z zastosowaniem zależności (8) oraz (11)-(13) we współrzędnych $q_{i}$ ma postać:

$$
\mathbf{J}^{a}(\mathbf{q})=\left[\begin{array}{ccccc}
-\left(l_{1}+l_{2} c_{2}+l_{3} c_{3}+d_{5} c_{4}\right) s_{1} & -l_{2} s_{2} c_{1} & -l_{3} s_{3} c_{1} & -d_{5} s_{4} c_{1} & 0 \\
\left(l_{1}+l_{2} c_{2}+l_{3} c_{3}+d_{5} c_{4}\right) c_{1} & -l_{2} s_{2} s_{1} & -l_{3} s_{3} s_{1} & -d_{5} s_{4} s_{1} & 0 \\
0 & l_{2} c_{2} & l_{3} c_{3} & d_{5} c_{4} & 0 \\
0 & 0 & 0 & s_{1} & c_{4} c_{1} \\
0 & 0 & 0 & -c_{1} & c_{4} s_{1} \\
1 & 0 & 0 & 0 & \mathrm{~s}_{4}
\end{array}\right] \frac{\Delta y}{\Delta x}
$$

gdzie: $s_{i}=\sin q_{i}, c_{i}=\cos q_{i}$.

Jakobian analityczny $\mathbf{J}^{a}(\mathbf{q})$ znajduje zastosowanie w praktycznych aplikacjach do obliczania wpływu sił i momentów występujących w końcówce manipulatora, określonych w układzie globalnym, na momenty w przegubach. Jeśli siły i momenty są mierzone za pomocą czujnika umieszczonego w końcówce manipulatora, to są one wyrażone w lokalnym układzie czujnika. Wówczas, w celu przeliczenia sił i momentów z miejsca pomiaru do przegubów manipula- 
tora, redukuje się zmierzony wektor sił i momentów do układu końcówki i wyraża się go w układzie globalnym, a następnie stosuje się jakobian analityczny. Innym rozwiązaniem jest zastosowanie jakobianu geometrycznego w ciele.

\section{Jakobian geometryczny $w$ ciele}

W celu poprawnego obliczenia wpływu sił i momentów wyrażonych np. w układzie czujnika siły umieszczonego w końcówce na siły i momenty w przegubach manipulatora można określić jakobian geometryczny w układzie ciała $\mathbf{J}^{b}(\mathbf{q})$, zwany krótko jakobianem geometrycznym w ciele [7].

Możliwy sposób wyznaczania jakobianu geometrycznego w ciele manipulatora $n$-członowego przedstawiono w pracy [7]. Jakobian taki składa się z kolumn $\mathbf{J}_{i}^{b}, i=1,2, \ldots, n$, czyli:

$$
\mathbf{J}^{b}(\mathbf{q})=\left[\begin{array}{lllll}
\mathbf{J}_{1}^{b} & \ldots & \mathbf{J}_{i}^{b} & \ldots & \mathbf{J}_{n}^{b}
\end{array}\right]
$$

gdzie kolumnę $\mathbf{J}_{i}^{b}$ definiuje się następująco:

$$
\mathbf{J}_{i}^{b}=\left[\begin{array}{c}
{\left[\mathbf{R}_{i-1}^{n T}\right]_{3 k o l} \times \mathbf{R}_{i-1}^{n T} \mathbf{p}_{i-1}^{n}} \\
{\left[\mathbf{R}_{i-1}^{n T}\right]_{3 k o l}}
\end{array}\right]
$$

w przypadku gdy przegub $i$-ty jest obrotowy lub

$$
\mathbf{J}_{i}^{b}=\left[\begin{array}{c}
{\left[\mathbf{R}_{i-1}^{n T}\right]_{3 k o l}} \\
\mathbf{0}
\end{array}\right]
$$

w przypadku gdy przegub $i$-ty jest pryzmatyczny.

Jakobian geometryczny w ciele wyprowadzony z zastosowaniem zależności (8) oraz (16)-(18) we współrzędnych $q_{i}$ ma postać:

$$
\mathbf{J}^{b}(\mathbf{q})=\left[\begin{array}{ccccc}
-\left(l_{1}+l_{2} c_{2}+l_{3} c_{3}+d_{5} c_{4}\right) s_{5} & l_{2} \tilde{c}_{42} c_{5} & l_{3} \tilde{c}_{43} c_{5} & d_{5} c_{5} & 0 \\
-\left(l_{1}+l_{2} c_{2}+l_{3} c_{3}+d_{5} c_{4}\right) c_{5} & -l_{2} \tilde{c}_{42} s_{5} & -l_{3} \tilde{c}_{43} s_{5} & -d_{5} s_{5} & 0 \\
0 & l_{2} \tilde{s}_{42} & l_{3} \tilde{s}_{43} & 0 & 0 \\
c_{4} c_{5} & 0 & 0 & s_{5} & 0 \\
-c_{4} s_{5} & 0 & 0 & c_{5} & 0 \\
s_{4} & 0 & 0 & 0 & 1
\end{array}\right]
$$

gdzie: $\tilde{s}_{i j}=\sin \left(q_{i}-q_{j}\right), \quad \tilde{c}_{i j}=\cos \left(q_{i}-q_{j}\right)$. 


\section{Konfiguracje osobliwe}

W zagadnieniach planowania trajektorii ruchu manipulatora istotnym zagadnieniem jest wyznaczenie konfiguracji osobliwych [3, 7, 9]. Z praktycznego punktu widzenia występowanie takich konfiguracji znacznie utrudnia rozwiązywanie zadania odwrotnego kinematyki, gdyż konieczne jest wówczas stosowanie złożonych metod matematycznych. W celu wyznaczenia konfiguracji osobliwych dokonuje się analizy jakobianu, przy czym analizując jakobian analityczny, można wyznaczyć konfiguracje osobliwe manipulatora, natomiast analizując jakobian geometryczny, można wyznaczyć również osobliwości reprezentacji kinematyki [7]. Jeśli liczba stopni swobody manipulatora jest mniejsza niż wymiar przestrzeni zadaniowej - tak jest w przypadku rozważanego manipulatora, to zgodnie z teorią wszystkie jego konfiguracje są osobliwe.

Gdyby jakobian był macierzą kwadratową, wystarczyłoby obliczyć jego wyznacznik i wyznaczyć zbiór konfiguracji osobliwych, przyrównując wyznacznik jakobianu do zera. Przedstawione jakobiany manipulatora nie są macierzami kwadratowymi, dlatego w celu wyznaczenia konfiguracji osobliwych określa się zestaw minorów stopnia 5. każdego jakobianu i poszukuje się konfiguracji, w których będą one równe zeru. Zestaw minorów stopnia 5. jakobianu analitycznego to:

$$
\mathbf{D}_{5}^{a}=\left(\begin{array}{c}
-l_{2} l_{3}\left(l_{1}+l_{2} \cos q_{2}+l_{3} \cos q_{3}+d_{5} \cos q_{4}\right) \sin \left(q_{3}-q_{2}\right) \cos q_{4} \\
-l_{2} l_{3}\left(l_{1}+l_{2} \cos q_{2}+l_{3} \cos q_{3}+d_{5} \cos q_{4}\right) \sin q_{1} \sin \left(q_{3}-q_{2}\right) \sin q_{4} \\
l_{2} l_{3}\left(l_{1}+l_{2} \cos q_{2}+l_{3} \cos q_{3}+d_{5} \cos q_{4}\right) \cos q_{1} \sin \left(q_{3}-q_{2}\right) \sin q_{4} \\
0 \\
l_{2} l_{3} \cos q_{1} \sin \left(q_{3}-q_{2}\right) \cos q_{4} \\
l_{2} l_{3} \sin q_{1} \sin \left(q_{3}-q_{2}\right) \cos q_{4}
\end{array}\right)
$$

z czego wynika, że zbiór konfiguracji osobliwych jest następujący:

$$
\mathbf{S}=\left\{\begin{array}{l}
\mathbf{q}=\left(\begin{array}{lllll}
q_{1} & q_{2} & q_{3} & q_{4} & q_{5}
\end{array}\right)^{T} \in \mathfrak{R}^{5} \\
\mid \sin q_{1}=0 \vee \cos q_{1}=0 \vee \sin \left(q_{3}-q_{2}\right)=0 \vee \sin q_{4}=0 \\
\vee \cos q_{4}=0 \vee l_{1}+l_{2} \cos q_{2}+l_{3} \cos q_{3}+d_{5} \cos q_{4}=0
\end{array}\right\}
$$

Zestaw minorów stopnia 5. jakobianu geometrycznego w ciele to: 


$$
\mathbf{D}_{5}^{b}=\left(\begin{array}{c}
0 \\
-l_{2} l_{3}\left(l_{1}+l_{2} \cos q_{2}+l_{3} \cos q_{3}+d_{5} \cos q_{4}\right) \sin \left(q_{3}-q_{2}\right) \sin q_{5} \\
-l_{2} l_{3}\left(l_{1}+l_{2} \cos q_{2}+l_{3} \cos q_{3}+d_{5} \cos q_{4}\right) \sin \left(q_{3}-q_{2}\right) \cos q_{5} \\
0 \\
-l_{2} l_{3} \sin \left(q_{3}-q_{2}\right) \cos q_{4} \cos q_{5} \\
l_{2} l_{3} \sin \left(q_{3}-q_{2}\right) \cos q_{4} \sin q_{5}
\end{array}\right)
$$

Wynika z niego zbiór konfiguracji osobliwych:

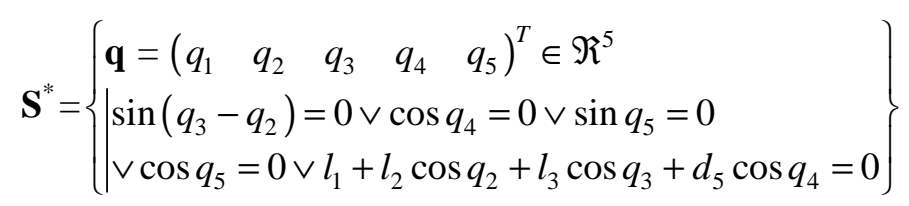

Zera w zestawach minorów (20) i (22) potwierdzają fakt, że rozpatrywany manipulator formalnie zawsze jest w konfiguracji osobliwej.

\section{Podsumowanie}

Przeprowadzona analiza kinematyki manipulatora umożliwia zaplanowanie trajektorii we współrzędnych konfiguracyjnych, która będzie następnie realizowana przez układ sterowania robota. W tym celu należy rozwiązać zadanie odwrotne kinematyki przy narzuconych zmianach pozycji i(lub) orientacji końcówki roboczej manipulatora. Do tego celu można zastosować równania kinematyki (10), z których należy wyznaczyć wektor prędkości przegubowych, a następnie, przez całkowanie, wektor współrzędnych przegubowych. Ponieważ $n<m$, czyli wymiar przestrzeni konfiguracyjnej jest mniejszy niż wymiar przestrzeni zadaniowej, nie jest możliwe osiąnięcie przez końcówkę roboczą dowolnego punktu przestrzeni zadaniowej z dowolną orientacją. Przeprowadzona analiza osobliwości stanowi wskazanie, jak należy planować zmiany pozycji i orientacji końcówki roboczej, aby manipulator nie osiagał konfiguracji osobliwych.

Znajomość jakobianów manipulatora jest szczególnie potrzebna w zagadnieniach sterowania ruchem robota, $\mathrm{z}$ uwzględnieniem interakcji $\mathrm{z}$ otoczeniem. Jest to sytuacja typowa m.in. dla różnych zadań montażowych oraz w przypadku zrobotyzowanej obróbki mechanicznej. W takim przypadku siły i momenty interakcji powinny być mierzone przykładowo przez czujnik umieszczony w końcówce roboczej, a znajomość jakobianów pozwala na obliczenie wpływu sił interakcji na siły i momenty w przegubach manipulatora oraz umożliwia poprawne sterowanie robotem. 


\section{Literatura}

[1] Gracia L., Tornero J.: Tracking Trajectories with a Robotic Manipulator with Singularities. LNCS, 4729 (2007), 595-605.

[2] Żylski W., Gierlak P.: Sterowanie ruchem nadążnym robotów manipulacyjnych. OW PRz, Rzeszów 2014.

[3] Penne R., Smet E., Klosiewicz P.: A short Note on Point Singularities for Robot Manipulators. J. Intell. Robot Syst., 62 (2011), 205-216.

[4] Kozłowski K., Dutkiewicz P., Wróblewski W.: Modelowanie i sterowanie robotów. Wydawnictwo Naukowe PWN, Warszawa 2003.

[5] Morecki A., Knapczyk J.: Podstawy robotyki. Teoria i elementy manipulatorów i robotów. WNT, Warszawa 1999.

[6] Spong M.W., Vidyasagar M.: Dynamika i sterowanie robotów. WNT, Warszawa 1997.

[7] Tchoń K. i in.: Manipulatory i roboty mobilne: modele, planowanie ruchu i sterowanie. Akademicka Oficyna Wydawnicza PLJ, Warszawa 2000.

[8] Selig J.M.: Geometric Fundamentals of Robotics, Springer Science+Business Media, New York 2005.

[9] Dulęba I.: Metody i algorytmy planowania ruchu robotów mobilnych i manipulacyjnych. AOW EXIT, Warszawa 2001.

\section{ANALYSIS OF THE KINEMATICS OF THE 5DOF MANIPULATOR}

\section{S u m m a r y}

In the paper the kinematics analysis of 5 degrees of freedom manipulator is presented. The analysis was realised for the Scorbot-ER 4pc robotic manipulator. To describe the kinematics of the manipulator the Denavit-Hartenberg notation is used. The kinematics scheme and parameters of the manipulator as well as appropriate transformation matrices, that were used in the further analysis, are given. The analytical Jacobian of the manipulator and the geometrical Jacobian in the body are determined and the analysis of singularities is realised. In singular manipulator's configurations the solution of the inverse kinematics problem is very difficult, and using classical methods - impossible. Therefore, knowledge of the singular configurations is necessary for the proper planning and generating the trajectory of the manipulator. The presented methodology is universal and can be used to analyze the kinematics of manipulators with a other kinematic structure that is not presented in this paper.

Keywords: Jacobian, singular configuration, Denavit-Hartenberg notation

DOI: $10.7862 / \mathrm{rm} .2014 .53$

Otrzymano/received: $10.06 .2014 \mathrm{r}$.

Zaakceptowano/accepted: 12.11.2014 r. 